\title{
Online WOM effects and product type: Evidence from Tmall
}

\author{
Qihua Liu
}

School of Information Technology, Jiangxi University of Finance and Economics, Nanchang, China

qh_liu@163.com

Keywords: Online WOM effects, Product type, online user reviews, Search products, Experience products

\begin{abstract}
This paper examines the persuasive effect and the awareness effect of online user reviews on product sales. Using publicly available data from a China-based B2C e-commerce site under the Alibaba Group-Tmall.com, we show that rating of online user reviews has no significant impact on product sales after controlling the influence of product price. However, we find that the review volume has significant and positive influence on product sales. More, to uncover the underlying mechanisms behind online WOM effects, we compare search products and experience products. Our results show that the effect of online user reviews is much larger for experience goods than for search goods. Our results also show that product price has no significant impact for search product, but has significant negative impact for experience products.
\end{abstract}

\section{Introduction}

Electronic commerce (e-commerce) has experienced a tremendous growth over the last decade. According to new figures from eMarketer, business-to-consumer (B2C) e-commerce sales worldwide will reach \$1.471 trillion in 2014, increasing nearly 20\% over 2013, and will reach $\$ 2.356$ trillion in 2018 [1]. As a result, the vast amount of products available on some e-commerce websites has created information overload among online users [2]. Some online retailers (e.g. Amazon.com, Tmall.com) have widely built online review system to assist consumers' decision making. Different from traditional word-of-mouth in interpersonal communication, online word-of-mouth (WOM) likely comes from unknown web shoppers and is, thus, deemed relatively objective [3]. So, many consumers read online reviews before buying products to reduce the risk and uncertainty of decision making [4]. The online review system is considered one of the key factors of the success of Amazon. Thus, online consumer reviews are recognized as an important source of information and a useful type of product recommendation [5].

Existing work in this area has analyzed the influence of online WOM on product sales. However, the results are mixed. Chen et al. (2004) empirically investigated the impacts of recommendations and consumer feedbacks on sales based on data gathered from Amazon.com [6]. Their results indicated that consumer ratings are not found to be related to sales. However, Chevalier and Mayzlin (2006) found that online user reviews had the significant and positive effect on book sales from a similar data source of Amazon.com [7].

Several reasons might contribute to the mixed results discovered in earlier studies. First, studies differ in their measurement of online WOM. Some studies working on the review volume, some focus on the user ratings, the rest think both the review volume and the user ratings are the points. Second, these studies collected data from different types of products. Some investigated the influence of online WOM on search products, but others investigated these effects on experience products. Finally, existing research is focused primarily on identifying the influence of online WOM, the influence of product price on sales usually ignored.

In this paper, we assess both the persuasive effect and the awareness effect of online user reviews in the context of search and experience products after controlling the influence of product price. In particular, we use publicly available data from a China-based B2C e-commerce site under the Alibaba Group-Tmall.com. 


\section{Hypotheses Development}

The online WOM meanly through two kinds of effects to impact consumers' beliefs about product quality and consequently spur sales: the persuasive effect and awareness effect. Awareness effects indicate that reviews convey the existence of the product and thereby put it in the choice set of consumers [5]. The persuasive effect is that the online WOM can change the customers' attitudes and evaluation towards the product and ultimately influence their purchase decision [5]. The review volume and user rating are the measurements of awareness effect and persuasive effect. The review volume respects the spread of product. The user ratings impress the evaluation of customers. Previous theoretical and empirical research provides support for the positive relationship between online user reviews and product sales. We therefore propose:

H1: Review volume has a significant and positive impact on product sales.

H2: User ratings have a significant and positive impact on product sales.

Most products available on Internet retail sites are generally categorized into search products and experience products. Search products refer to the products whose quality is relatively easier to ascertain before consumption. Experience products refer to the products whose quality is relatively difficult to ascertain before direct experience. Because of the inherent difficulty associated with the evaluation of experience products prior to purchasing online, consumers tend to feel uncertain as to whether the products would meet their expectations.

Product type can also influence consumer choices and purchase behavior at an e-commerce website. Prior research has shown that consumers evaluating a search good were more likely to use own-based decision-making processes; in contrast, those evaluating an experience product tended to use other-based decision-making processes. Online user review provides attitudes and opinions of exceeding purchasers, and can significantly influence the followers' decision making, especially when online users have limited information about product value and usability. So, in e-commerce environment, WOM effects might be more salient for experience products than for search products. Based on this, we propose the following hypotheses:

H3. Online WOM effects might be more salient for experience products than for search goods.

\section{Data and Empirical Methodology}

\section{Data and variables}

This empirical study is established in the context of online purchase behaviors at Tmall.com(www.tmall.com) of Alibaba Group. Through navigation search, lady jeans under clothing category and parent-child books under books category in Tmall are respectively selected to represent experience products and search products and serve as objects of our study. For these two kinds of products, we both obtained relevant information - including name, cumulative sales, price, online review volume, and user rating. From October 25, 2014 to November 24, 2014, between the hours 8:00 p.m. and 10:00 p.m., we collected the data of top 300 ladies jeans base on comprehensive ranking. To guarantee the validity of the study, we rejected the following samples: review volume is less than or equal to three, review rating is zero and duration in comprehensive top 300 lists is less than seven days. After eliminating these samples, we got 4270 data consisting of 313 ladies jeans. From March 10, 2015 to April 10, 2015, between the hours 8:00 p.m. and 10:00 p.m., we collected the data of top 300 parent-child books based on comprehensive ranking. Adopting the same handling method in clothing data, we obtained 4744 data containing 284 parent-child books.

The key dependent variable in our empirical analysis is $\mathrm{IS}_{\mathrm{it}}$, which represents incremental sales of product $\mathrm{i}$ during the $\mathrm{t}$ time appearance against the $\mathrm{t}-1$ time appearance in the top 300 list. Our major independent variables include Volume ${ }_{\mathrm{i}, \mathrm{t}-1}$, Rating $\mathrm{i}_{\mathrm{i}, \mathrm{-}-1}$, and $\mathrm{P}_{\mathrm{i}, \mathrm{t}-\mathrm{1}}$. Among them, Volume $\mathrm{i}_{\mathrm{i}, \mathrm{-}-1}$, Rating $\mathrm{i}_{\mathrm{i}, \mathrm{t}-1}$, and $\mathrm{P}_{\mathrm{i}, \mathrm{t}-1}$, which respectively represents the review volume, user rating and price of product $i$ in number $t-1$. To prevent the abnormality that the result is zero during natural logarithm processing as well, we used $\left(\mathrm{IS}_{\mathrm{i}, \mathrm{t}}+2\right)$ to replace $\mathrm{IS}_{\mathrm{i}, \mathrm{t}}$, and re-named it as IS_2 $2_{\mathrm{i}, \mathrm{t}}$. In order to control the influence of 
potential outliers to make the regression results more objective, we do linear transformation of natural logarithm for all the continuous variables. Table 1 presents the descriptive statistics.

Table 1. Data descriptive statistics

\begin{tabular}{|l|c|c|c|c|c|c|}
\hline \multicolumn{1}{|c|}{ Variable } & N & Mean & Median & S.D. & Min. & Max. \\
\hline Lady jeans & & & & & & \\
IS $_{i, t}$ & 4270 & 354.990 & 64.000 & 1238.416 & 0 & 32912 \\
Volume $_{i, t-1}$ & 4270 & 14245.030 & 3495.000 & 33814.466 & 15 & 1130171 \\
Rating $_{i, t-1}$ & 4270 & 4.729 & 4.700 & 0.100 & 4.200 & 5 \\
$\mathrm{P}_{i, t-1}$ & 4270 & 87.419 & 79.0000 & 47.074 & 7.900 & 269 \\
\hline Parent-child books & & & & & & \\
IS $_{i, t}$ & 4744 & 3.960 & 0 & 36.053 & 0 & 1646 \\
Volume $_{i, t-1}$ & 4744 & 586.300 & 118.500 & 1164.962 & 3 & 9041 \\
Rating $_{i, t-1}$ & 4744 & 4.886 & 4.900 & 0.088 & 4.200 & 5 \\
$\mathrm{P}_{i, t-1}$ & 4744 & 35.346 & 31.800 & 21.761 & 6.700 & 251 \\
\hline
\end{tabular}

\section{Empirical Model}

We model the influence of online WOM (review volume and user rating) and product price on product sales (incremental sales). The panel-level empirical model is specified in Eq. (1):

LnIS _ $2_{i, t}=\alpha_{i}+\beta_{1}$ LnVolume $_{i, t-1}+\beta_{2}$ LnRating $_{i, t-1}+\gamma_{1} L n P_{i, t-1}+\varepsilon_{i, t}$

Where $\alpha_{i}$ is the unobserved disturbance term which is assumed to be orthogonal to other independent variables; $\beta_{1}, \beta_{2}$, and $\gamma_{1}$ are the model coefficients; and $\varepsilon_{i, t}$ is the error term.

\section{Results and discussions}

We took $L n I S_{-} 2_{i, t}$ as an independent variable, estimated Eq. (1) with EViews7.2, and, respectively, obtained the fixed effects panel data estimation results of the two samples (lady jeans and parent-child books), as shown in Table 2.

Table 2 Fixed effects estimation results

\begin{tabular}{|l|l|l|}
\hline Variable & $\begin{array}{l}\text { Experience product } \\
\text { (lady jeans) }\end{array}$ & $\begin{array}{l}\text { Search product } \\
\text { (parent-child books) }\end{array}$ \\
\hline LnVolume $_{\mathrm{i}, \mathrm{t}-1}$ & $0.333^{* * *}$ & $0.083^{* *}$ \\
& $(0.036)$ & $(0.039)$ \\
\hline LnRating $_{\mathrm{i}, \mathrm{t}-1}$ & 1.984 & -1.855 \\
& $(1.860)$ & $(1.674)$ \\
\hline $\mathrm{LnP}_{\mathrm{i}, \mathrm{t}-1}$ & $-0.402^{* *}$ & -0.218 \\
& $(0.177)$ & $(0.307)$ \\
\hline & $\mathrm{N}=313$ & $\mathrm{~N}=284$ \\
& Group $=4270$ & Group=4744 \\
& $\mathrm{R}^{2}=0.784$ & $\mathrm{R}^{2}=0.329$ \\
\hline
\end{tabular}

Notes: $L n I S \_{ }_{i, t}$ as the Independent variable. Standard errors in parentheses. ${ }^{*} \mathrm{p}<0.10,{ }^{* *} \mathrm{p}<0.05,{ }^{* * *} \mathrm{p}<0.01$

According to the regression analysis results, we found that the coefficients of LnVolume Lit-1 $_{1}$ in two samples were significant and positive. Our analysis indicated that product sales are strongly affected by the number of online user reviews, supporting $\mathrm{H} 1$. The coefficients of LnRating $\mathrm{i}_{\mathrm{i}, \mathrm{t}-1}$ in two samples were insignificant, which refuted H2. The results showed that online user reviews have little persuasive effect on consumer purchase decisions, but have strong awareness effect on product sales. This is similar to the results of Duan et al. (2008) [5].

We also found that estimated coefficient of LnVolume $_{\mathrm{i}, \mathrm{t}-1}$ for search goods is much smaller than that for experience goods ( 0.083 vs. 0.333 ). The comparison result suggested that the online WOM effect is more prominent for experience goods than for search, which supported H3. This is inconsistent with the results of $\mathrm{Li}$ and $\mathrm{Wu}$ (2012) [8]. Their study showed that the effect of Facebook-mediated WOM does not significantly differ between the two product categories. The study of Li and Whu (2012) used Facebook-mediated WOM, while our study used traditional WOM, 
which might be the reason why the mixed results occurred. Social media WOM would have the tremendous power to reach far more people than the WOM created among a close group of friends. Compared to traditional WOM, social media WOM is more likely to increase product awareness as opposed to updating consumers' beliefs, so the effect of Facebook-mediated WOM is similar between the two product categories [8].

The coefficient of $\mathrm{LnP}_{\mathrm{i}, \mathrm{t}-1}$ for experience product is significantly negative, but for search product is insignificant. The result indicated that product price had significant negative impact for experience products, but had no impact on users' choice for search product.

\section{Conclusions}

In this paper, we collected data from Tmall and employed a fixed-effect regression model to compare the online WOM effects between experience products and search products, which contributed to the research on WOM effects. Our results showed that rating of online user reviews had no significant impact on product sales after controlling the influence of product price. However, we found that the review volume had significant and positive influence on product sales. Moreover, we also found that the effect of online user reviews is much larger for experience goods than for search goods. Our results also showed that product price had no significant impact for search product, but had significant negative impact for experience products.

\section{Acknowledgements}

This paper is supported by the Humanities and Social Sciences Foundation of the Ministry of Education of China (No: 13YJC630094).

\section{References}

[1] eMarketer. Worldwide Ecommerce Sales to Increase Nearly 20\% in 2014. July 23, 2014. on http://www.emarketer.com/Article/Worldwide-Ecommerce-Sales-Increase-Nearly-20-2014/101 1039

[2] W. Duan, A.B. Whinston, Informational cascades and software adoption on the internet: an empirical investigation, MIS Quarterly. 33 (2009) 23-48

[3] Q. Liu, L. Zhang, Information cascades in online reading: an empirical investigation of panel data, Library Hi Tech. 32 (2014) 687-705

[4] C. Derbaix, J. Vanhamme, Inducing word-of-mouth by eliciting surprise-a pilot investigation, Journal of Economic Psychology. 24 (2003) 99-116

[5] W. Duan, B. Gu, A.B. Whinston, Do online reviews matter?-An empirical investigation of panel data, Decision Support Systems. 45 (2008) 1007-1016

[6] P.Y. Chen, S.Y. Wu, J. Yoon, The impact of online recommendations and consumer feedback on sales, Proceedings of the 25th International Conference on Information Systems, Washington, DC, pp. 711-724

[7] J.A. Chevalier, D. Mayzlin, The effect of word of mouth on sales: Online book reviews, Journal of Marketing Research. 43 (2006) 345-354

[8] X. Li, L. Wu, Herding and Social Media Word-of-Mouth: Evidence from Groupon. Best Paper Award HICSS, 2013; WISE 2012 